\title{
Chemoradiotherapy for patients with locally advanced or unresectable extra-hepatic biliary cancer
}

\author{
Krishan R. Jethwa ${ }^{1,2 \#, ~ S h i l p a ~ S a n n a p a n e n i ~}{ }^{3 \#}$, Trey C. Mullikin², William S. Harmsen ${ }^{4}$, Molly M. Petersen ${ }^{4}$, \\ Phanindra Antharam ${ }^{2}$, Brady Laughlin ${ }^{5}$, Amit Mahipal ${ }^{6}$, Thorvardur R. Halfdanarson ${ }^{6}$, Kenneth W. Merrell ${ }^{2}$, \\ Michelle Neben-Wittich ${ }^{2}$, Terence T. Sio ${ }^{5}$, Michael G. Haddock ${ }^{2}$, Christopher L. Hallemeier ${ }^{2}$ \\ ${ }^{1}$ Department of Therapeutic Radiology, Yale University School of Medicine, New Haven, CT, USA; ${ }^{2}$ Department of Radiation Oncology, Mayo \\ Clinic, Rochester, MN, USA; ${ }^{3}$ Department of Internal Medicine, Texas Health Presbyterian Hospital, Dallas, TX, USA; ${ }^{4}$ Department of Biomedical \\ Statistics and Informatics, Mayo Clinic, Rochester, MN, USA; ${ }^{5}$ Department of Radiation Oncology, Mayo Clinic, Phoenix, AZ, USA; ${ }^{6}$ Department \\ of Medical Oncology, Mayo Clinic, Rochester, MN, USA \\ Contributions: (I) Conception and design: All authors; (II) Administrative support: None; (III) Provision of study materials or patients: All authors; \\ (IV) Collection and assembly of data: KR Jethwa, S Sannapaneni, TC Mullikin, WS Harmsen, MM Petersen, P Antharam, CL Hallemeier; (V) Data \\ analysis and interpretation: All authors; (VI) Manuscript writing: All authors; (VII) Final approval of manuscript: All authors. \\ \#These authors contributed equally to this work. \\ Correspondence to: Krishan R. Jethwa, MD. Department of Therapeutic Radiology, Yale University School of Medicine, New Haven, CT. 15 York \\ Street, PO Box 208040, New Haven, CT, USA. Email: krishan.jethwa@yale.edu; Christopher L. Hallemeier, MD. Department of Radiation \\ Oncology, Mayo Clinic, 200 First St SW, Rochester, MN 55905, USA. Email: hallemeier.christopher@mayo.edu.
}

Background: Although surgical resection is the preferred curative-intent treatment option for patients with non-metastatic, extra-hepatic biliary cancer (EBC), radiotherapy (RT) or chemoradiotherapy (CRT) may be utilized in select cases when surgical resection is not feasible. The purpose of this study is to report the efficacy and adverse events (AEs) associated with CRT for patients with locally advanced and unresectable EBC.

Methods: This was a retrospective cohort study of patients with EBC, including extra-hepatic cholangiocarcinoma or gallbladder cancer, deemed inoperable who received RT between 1998 and 2018. The median RT dose was 50.4 Gy in 28 fractions and 94\% received concurrent 5-fluorouracil. The KaplanMeier method was used to estimate overall survival (OS) and progression-free survival (PFS) from the start of RT. The cumulative incidence of local progression (LP), locoregional progression (LRP), and distant metastasis (DM) were reported with death as a competing risk. Cox proportional hazards regression models were used to assess for correlation between patient and treatment characteristics and outcomes.

Results: Forty-eight patients were included for analysis. The median OS was 12.0 months [95\% confidence interval (CI): 2.3-73.2 months]. The 2-, 3-, and 5-year OS were 33\% (95\% CI: 22-50\%), 20\% (95\% CI: 11-36\%), and 7\% (95\% CI: 2-20\%), respectively. The 2-year PFS, LP, LRP, and DM were 21\% (95\% CI: 12-36\%), 27\% (95\% CI: 17-44\%), 31\% (95\% CI: 20-48\%), and 33\% (95\% CI: 22-50\%), respectively. On univariate analysis, biologically effective dose (BED) $>59.5 \mathrm{~Gy}_{10}$ was associated with improved OS [hazard ratio (HR): 0.40, 95\% CI: 0.18-0.92, $\mathrm{P}=0.03$ ] and PFS (HR: 0.37, 95\% CI: 0.16-0.84, $\mathrm{P}=0.02$ ) and primary tumor size (per $1 \mathrm{~cm}$ increase) was associated with worsened PFS (HR: 1.29, 95\% CI: 1.02-1.63, P=0.04). BED > 59.5 Gy $\mathrm{G}_{10}$ remained associated with PFS on multivariate analysis (HR: 0.34, 95\% CI: 0.15-0.78, $\mathrm{P}=0.01$ ). Treatment-related grade $3+$ acute and late gastrointestinal AEs occurred in $13 \%$ and $17 \%$ of patients, respectively.

Conclusions: RT is associated with 3- and 5-year survival in a subset of patients with unresectable EBC. Further exploration of the role of RT as part of a multi-modality curative treatment strategy is warranted.

Keywords: Radiotherapy (RT); cholangiocarcinoma; biliary cancer

Submitted Jun 26, 2020. Accepted for publication Sep 21, 2020.

doi: 10.21037/jgo-20-245

View this article at: http://dx.doi.org/10.21037/jgo-20-245

(c) Journal of Gastrointestinal Oncology. All rights reserved. 


\section{Introduction}

The most well-established curative-intent therapy for patients with extra-hepatic biliary cancer (EBC), including extra-hepatic cholangiocarcinoma or gallbladder cancer, is radical, margin-negative, surgical resection with the consideration for post-operative chemotherapy with or without RT, depending upon risk factors (1-4). However, the prognosis for patients with locally advanced, unresectable EBC remains poor with the primary treatment consisting of multi-agent chemotherapy (5).

A number of series have reported outcomes of radiotherapy (RT) or chemoradiotherapy (CRT) for patients with unresectable EBC (6-30). These series report local control (LC) of approximately $50-70 \%$, median survival of 10-24 months, and 3-year overall survival (OS) of 10-20\%, with survival limited by competing risks of local and distant disease relapse and underlying medical comorbidities and complications. RT has also demonstrated a palliative role in preventing or alleviating biliary obstruction (20-23). Unfortunately, patients are at a high risk of both disease and treatment-related morbidity with grade 3 or higher acute adverse events (AEs) of $20-30 \%$ and potential late complications including gastroduodenal ulceration or bleeding in $10-20 \%(6-30)$. Biliary and liver infection is tumor-related and fairly ubiquitous in this cohort with reported rates of severe infection as high as $60 \%$ (31).

Interestingly, many of the aforementioned series demonstrate long-term survival in a subset of patients, indicative of a potentially select subgroup for whom disease biology or treatment-related factors may be associated with sustained disease control and long-term survival. However, the role of RT for patients with unresectable EBC remains inconclusive. The purpose of this series is to report the therapeutic efficacy, AEs, and disease and treatmentrelated associates with outcomes for a cohort of patients with unresectable EBC treated with RT. We present the following article in accordance with the STROBE reporting checklist (available at http://dx.doi.org/10.21037/ jgo-20-245).

\section{Methods}

\section{Patient population}

The study was conducted in accordance with the Declaration of Helsinki (as revised in 2013). The study was approved by our institutional review board of the Mayo Clinic in Rochester, Minnesota (No. 18-003400) as a retrospective study deemed as minimal risk and exempt of the need for informed consent for individual participants included in the study.

We performed a single institution retrospective cohort study of patients with histologically or cytologically confirmed EBC, including extra-hepatic cholangiocarcinoma or gallbladder cancer, who received RT between 1998 and 2018. Patients were excluded if they were less than 18 years of age, had distant metastatic disease, were initially deemed suitable for any form of curativeintent surgical resection including radical resection or radical resection followed by liver transplantation (32), had prior abdominal RT, or did not provide research consent.

\section{Pre-treatment evaluation}

All patients underwent pre-treatment evaluation within a specialized multi-disciplinary practice including gastroenterology, surgical oncology, medical oncology, and radiation oncology. Assessments included history and physical examinations, diagnostic evaluation including CA 19-9 (94\%), and computed tomography (CT) of the abdomen and pelvis (100\%). Magnetic resonance imaging (MRI) abdomen was obtained in $58 \%$ of patients. Systemic imaging assessments included evaluation of the chest with chest X-ray alone (54\%) or CT chest (42\%), and positron emission tomography-computed tomography (PET-CT) was performed in $13 \%$ of patients. Patients underwent endoscopic retrograde cholangiopancreatography (ERCP) for local disease characterization with the addition of internal biliary stent placement $(90 \%)$ or percutaneous biliary drainage (4\%) for those with clinically significant biliary obstruction.

\section{Treatment techniques}

All patients underwent CT-based simulation with immobilization devices and optional respiratory motionmanagement strategies as deemed appropriate by the treating physician. When indicated, additional diagnostic studies such as MRI abdomen, contrast-enhanced CT, or PET-CT were registered to the planning CT to assist with target delineation.

Target volumes included the internal gross tumor volume (iGTV), which consisted of the gross primary tumor and clinically involved regional lymph nodes accounting for respiratory motion on a 4-dimensional CT scan, when indicated. The clinical target volume (CTV) consisted 
of a 5-10 mm expansion upon the iGTV to encompass microscopic disease extension and most patients had elective inclusion of regional lymph nodes, such as the porta hepatis and celiac lymph nodes. A 5-10 mm margin was added to the CTV to generate the planning target-volume (PTV).

External beam RT (EBRT) was delivered with threedimensional conformal radiotherapy (3DCRT) or intensity modulated radiotherapy (IMRT) most commonly to a dose of 50.4 Gy in 28, once-daily fractions, or 45 Gy in 30, twice daily, fractions. Concurrent chemotherapy was delivered in $94 \%$ of patients and included either 5 -flourouracil or capecitabine. Eight patients received intraluminal biliary low-dose rate (LDR) or high-dose rate (HDR) brachytherapy prescribed to a dose of 20-25 Gy (LDR) or $9.3 \mathrm{~Gy}$ (HDR) at 1-cm depth.

\section{Patient assessments}

Patients underwent oncologic surveillance at 3 to 6-month intervals as part of routine clinical care with history and physical examination, laboratory evaluation, and diagnostic imaging. Local progression (LP) was defined as progression at the primary tumor site; regional progression was defined as recurrence or progression within non-metastatic regional lymph nodes; distant metastasis (DM) sites were defined as non-regional lymph nodes or distant organs. Disease recurrence was diagnosed histologically, or when unavailable, clinically per radiographic findings. AEs of treatment were assessed and attributed per Common Terminology Criteria for AEs version 4.0 (CTCAE). Acute AEs were defined as those occurring during RT or within 3 months of RT completion. Late AEs were defined as any complication which occurred greater than 3 months following completion of RT.

\section{Statistical analysis}

Statistical analysis was performed using SAS version 9.4 (SAS Institute Inc., Cary, NC). OS and progression-free survival (PFS) from the start of RT were estimated using the Kaplan-Meier method. The cumulative incidences of LP, locoregional progression (LRP), DM, and late AEs were reported using the competing risk model, with death as a competing risk. Baseline patient, tumor, and treatment characteristics associated with OS and PFS were assessed using a univariate Cox proportional hazards regression model. EBRT biologically effective dose (BED) was calculated using the linear-quadratic model assuming an $\alpha /$ $\beta$ of 10 Gy. Associations between BED and outcomes were assessed by stratifying by the median BED of $59.5 \mathrm{~Gy}_{10}$ (equivalent to 50.4 Gy in 28 fractions). Multivariate Cox proportional hazards regression models were examined for the outcomes of OS and PFS, including as candidate variables those with a univariate significance of $\mathrm{P}<0.15$. A backward selection method was used to identify a parsimonious model. The alpha-level was set at 0.05 for statistical significance. Significance tests (P values) were not adjusted for multiple testing. Patterns of disease progression were reported descriptively. Patients dependent upon biliary stenting prior to RT were assessed for the ability to transition to stent-free, defined as being stent-free for at least a 3-month period following RT.

\section{Results}

A total of 48 patients met study inclusion criteria and were included for analysis. Patient and treatment characteristics are demonstrated in Tables 1,2. No patient underwent surgical resection or resection with liver transplantation following RT.

\section{Survival and disease control}

The median patient follow-up duration was 13 months [interquartile range (IQR): 6-29]. The median OS was 12.0 months [95\% confidence interval (CI): $2.3-$ 73.2 months]. The 2-, 3-, and 5-year OS were 33\% (95\% CI: $22-50 \%), 20 \%$ (95\% CI: $11-36 \%)$, and $7 \%$ (95\% CI: $2-20 \%)$, respectively. The median and 2-year PFS were 9.0 months (95\% CI: $1.7-73.2$ months) and 21\% (95\% CI: $12-36 \%)$ (demonstrated in Table 3 and Figure 1), respectively. The cause of death was cancer-related in 38 (79\%) patients, non-cancer-related in $9(19 \%)$ patientsmost commonly due to liver or biliary infection (56\%), and was unknown in 1 patient $(2 \%)$.

\section{Associates with outcomes}

On univariate analysis (demonstrated in Table 4), EBRT $\mathrm{BED}>59.5 \mathrm{~Gy}_{10}$ was associated with improved OS (HR: $0.40,95 \%$ CI: $0.18-0.92, \mathrm{P}=0.03)$ and PFS (HR: 0.37 , 95\% CI: 0.16-0.84, $\mathrm{P}=0.02$ ) (demonstrated in Figure 2), and increasing tumor size per $1 \mathrm{~cm}$ was associated with poorer PFS (HR: 1.29, 95\% CI: 1.02-1.63). When RT regimens were assessed as an EBRT BED $\leq 59.5 \mathrm{~Gy}_{10}$ vs. EBRT BED $\leq 59.5 \mathrm{~Gy}_{10}+$ brachytherapy boost $v s$. EBRT 
Table 1 Baseline patient characteristics

\begin{tabular}{lc}
\hline Variable & Value $^{*}$ \\
\hline Age (years) & $67(60$ to 71$)$ \\
Sex & \\
Male & $31(65 \%)$ \\
Female & $17(35 \%)$
\end{tabular}

History of inflammatory bowel disease or primary sclerosing cholangitis

$\begin{array}{lc}\text { No } & 40(83 \%) \\ \text { Yes } & 8(17 \%) \\ \text { ECOG status } & \\ 0 & 17(35 \%) \\ 1 & 24(50 \%) \\ 2 & 3(6 \%) \\ 3 & 2(4 \%) \\ 4 & 1(2 \%) \\ \text { Unknown } & 1(2 \%) \\ \text { Reason for inoperability } & \\ \text { Anatomical } & 42(88 \%) \\ \text { Medical } & 6(12 \%)\end{array}$

Baseline biliary obstruction requiring stenting

$\begin{array}{lc}\text { No } & 3(6 \%) \\ \text { Yes } & 45(94 \%) \\ \text { Tumor location } & \\ \text { Extra-hepatic bile duct } & 71(85 \%) \\ \text { Gallbladder } & 7(15 \%) \\ \text { Tumor size }(\mathrm{cm}) & 3.2(2.5 \text { to } 4.4) \\ \text { T-stage } & 7(15 \%) \\ 1 & 13(27 \%) \\ 2 & 15(31 \%) \\ 3 & 13(27 \%) \\ 4 & \\ \mathrm{~N}-\text {-stage } & 38(71 \%) \\ \mathrm{CN} 0 & 14(29 \%) \\ \mathrm{CN}+ & 136(45 \text { to } 420) \\ \text { Baseline } \mathrm{CA} 19-9(\mathrm{U} / \mathrm{mL}) & \end{array}$

*, continuous variables reported as median (interquartile range); categorical variables reported as number (\%). ECOG, Eastern Cooperative Oncology Group.
Table 2 Treatment characteristics

\begin{tabular}{|c|c|}
\hline Variable & Value \\
\hline \multicolumn{2}{|l|}{ EBRT technique } \\
\hline 3DCRT & $38(79 \%)$ \\
\hline IMRT & $10(21 \%)$ \\
\hline \multicolumn{2}{|l|}{ Elective lymph node irradiation } \\
\hline No & $4(8 \%)$ \\
\hline Yes & $44(92 \%)$ \\
\hline \multicolumn{2}{|l|}{ EBRT fractionation } \\
\hline Once-daily & $33(69 \%)$ \\
\hline Twice-daily & $15(31 \%)$ \\
\hline EBRT dose (Gy) & 50.4 (45 to 50.4$)$ \\
\hline EBRT fractions & 28 (28 to 30$)$ \\
\hline EBRT BED (Gy10) & 59.5 (52 to 59.5$)$ \\
\hline \multicolumn{2}{|l|}{ Biliary brachytherapy boost* } \\
\hline No & $40(83 \%)$ \\
\hline Yes & $8(17 \%)$ \\
\hline \multicolumn{2}{|l|}{ RT regimen } \\
\hline EBRT BED $\leq 59.5 \mathrm{~Gy}_{10}$ & $32(67 \%)$ \\
\hline EBRT BED >59.5 $\mathrm{Gy}_{10}{ }^{\#}$ & $9(19 \%)$ \\
\hline EBRT BED $\leq 59.5$ Gy $_{10}$ plus brachytherapy & $7(14 \%)$ \\
\hline \multicolumn{2}{|l|}{ Chemotherapy } \\
\hline Prior to RT & $2(4 \%)$ \\
\hline Concurrently with RT & $45(94 \%)$ \\
\hline Following RT & $5(10 \%)$ \\
\hline
\end{tabular}

Continuous variables reported as median (interquartile range). Categorical variables reported as number (\%). *, most commonly 20-25 Gy (low-dose rate) or 9.3 Gy (high-dose rate) in 1 fraction prescribed to $1 \mathrm{~cm}$ depth; ", median BED 70 Gy10 (range, 62-98) delivered with regimens of 52.2-67.5 Gy in 15-35 fractions. One patient received EBRT BED $\geq 59.5$ Gy10 plus brachytherapy. EBRT, external beam radiotherapy; 3DCRT, three-dimensional conformal radiotherapy; IMRT, intensity modulated radiotherapy; $\mathrm{RT}$, radiotherapy; $\mathrm{BED}$, biologically effective dose.

$\mathrm{BED}>59.5 \mathrm{~Gy}_{10}$ to compare techniques of local dose escalation, EBRT BED >59.5 $\mathrm{Gy}_{10}$ remained associated with improved OS (HR: 0.41, 95\% CI: 0.18-0.94, $\mathrm{P}=0.04$ ), and PFS (HR: $0.34,95 \%$ CI: $0.15-0.78, \mathrm{P}=0.01$ ) but the addition of brachytherapy did not. On multivariate analysis, EBRT BED >59.5 Gy $\mathrm{y}_{10}$ was associated with improved PFS 
Table 3 Oncologic efficacy

\begin{tabular}{lcc}
\hline Oncologic efficacy & Median (months) $(95 \% \mathrm{Cl})$ & 2-year $(95 \% \mathrm{Cl})$ \\
\hline OS & $12.0(2.3$ to 73.2$)$ & $33 \%(22$ to 50$)$ \\
PFS & $9.0(1.7$ to 73.2$)$ & $21 \%(12$ to 36$)$ \\
LP & - & $27 \%(17$ to 44$)$ \\
LRP & - & $31 \%(20$ to 48$)$ \\
DM & - & $33 \%(22$ to 50$)$ \\
\hline
\end{tabular}

$\mathrm{Cl}$, confidence interval; OS, overall survival; PFS, progressionfree survival; LP, local progression; LRP, locoregional progression; DM, distant metastasis.

(HR: $0.34,95 \%$ CI: $0.15-0.78, \mathrm{P}=0.01$ ). No variable was associated with $\mathrm{OS}$ on multivariate analysis.

\section{Patterns of disease progression}

Twenty-five (52\%) patients were identified with disease progression by last radiographic follow-up. The 2-year cumulative incidences of LP, LRP, and DM were 27\% (95\% CI: $17-44 \%$ ), $31 \%$ (95\% CI: $20-48 \%$ ), and $33 \%$ (95\% CI: $22-50 \%$ ), respectively (demonstrated in Table 3 and Figure 1C,D,E). Patterns of first progression included: DM $(\mathrm{n}=8,17 \%)$, local only $(\mathrm{n}=7,15 \%)$, local $+\mathrm{DM}(\mathrm{n}=4,8 \%)$, local + regional $+\mathrm{DM}(\mathrm{n}=3,6 \%)$, regional $+\mathrm{DM}(\mathrm{n}=2,4 \%)$, or local + regional $(\mathrm{n}=1,2 \%)$. Isolated locoregional firstprogression occurred in $8(32 \%)$ patients. An equal number of patients experienced locoregional first-progression $(n=17$, $35 \%)$ as DM first-progression ( $\mathrm{n}=17,35 \%)$. The majority of patients $(92 \%)$ received elective regional lymph node irradiation and no patient experienced an isolated regionalonly first-progression.

\section{AEs}

Of the 48 total patients, 1 (2\%) patient discontinued treatment early after having received 43.2 Gy of a planned 50.4 Gy, 3 (6\%) patients required an unintended midtreatment break, and $9(19 \%)$ patients were hospitalized during RT. Of these, 2 patients were hospitalized due to RT-related toxicities, including one patient with severe nausea and vomiting and another patient with severe abdominal pain, 4 patients were hospitalized due to liver or biliary infection, and 2 patients were hospitalized due to medical complications unrelated to RT (one who required monitoring due to supratherapeutic anti-coagulation and a second patient who experienced a mid-treatment cerebrovascular accident). Acute grade 3 or higher treatment-related gastrointestinal (GI) AEs occurred in $13 \%$ of patients. The 2 -year cumulative incidence of late grade 3 or higher GI complications was $27 \%$ (95\% CI: 13-36\%), with $17 \%$ (95\% CI: 5-27\%) attributable to RT (demonstrated in Table 5). Treatment-related AEs included: stomach or small bowel ulceration (2\%, 95\% CI: 0-6\%), small bowel obstruction (2\%, 95\% CI: 0-6\%), or GI bleed (15\%, 95\% CI: 4-24\%). No patient experienced treatmentrelated bowel perforation or fistula, and no patient experienced a grade 5 toxicity. No differences in acute $(\mathrm{P}=0.27)$ or late $(\mathrm{P}=0.59)$ GI AEs were identified amongst patients treated with EBRT BED $\leq 59.5 \mathrm{~Gy}_{10}$, EBRT BED $>59.5 \mathrm{~Gy}_{10}$, or EBRT BED $\leq 59.5 \mathrm{~Gy}_{10}$ plus brachytherapy.

The 2-year cumulative incidence of biliary infection following RT was $46 \%$ (95\% CI: $30-58 \%$ ). Of the 45 (94\%) patients dependent upon biliary decompression or stenting prior to RT, 1 was able to become stent-free after completion of RT and remained stent-free for 7 months until death from non-cancer causes. The 3 patients who did not require pre-treatment biliary stenting all remained stent-free following RT.

\section{Discussion}

We report our institutional experience of RT for patients with locally advanced EBC who were deemed inoperable by conventional surgical techniques and not suitable for radical resection with liver transplantation. We identified 3 - and 5-year survival in a subset of patients and that BED $>59.5 \mathrm{~Gy}_{10}$ (equivalent to a dose of $50.4 \mathrm{~Gy}$ in 28 fractions) was associated with improved OS on univariate analysis and improved PFS on both univariate and multivariate analyses. Despite this, patients are at considerable risk of tumor- and treatment-related morbidities, thus suggesting that improvements in patient selection and medical, supportive, and cancer-directed care are needed to further maximize the therapeutic gains of local RT for patients with unresectable EBC.

The majority of data describing RT for patients with EBC are limited to relatively small, single institution series (demonstrated in Table S1) (6-30). Foo et al. reported on 24 patients treated between 1980-1991 with EBRT to a median dose of 50.4 Gy in 28 fractions plus biliary brachytherapy with concurrent 5-FU chemotherapy in 38\% of patients (6). They demonstrated 5 -year OS of $14 \%$ with a trend towards improved OS for patients who received 
A

Overall survival

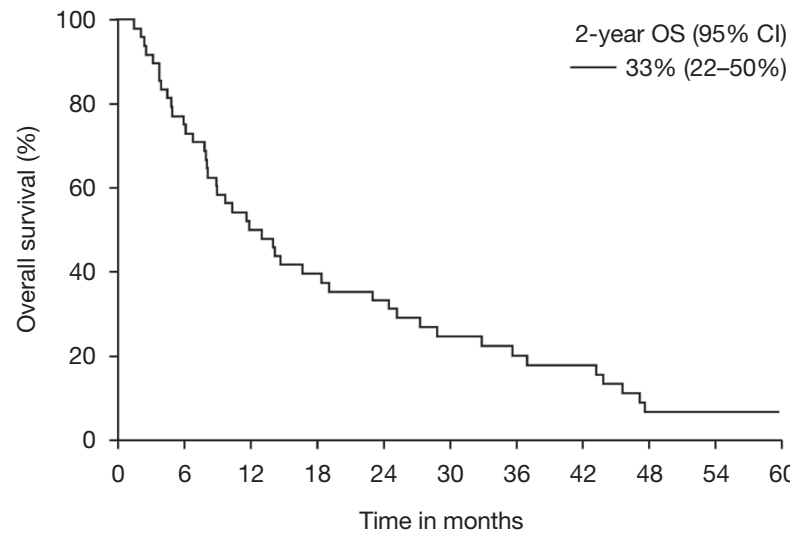

No. at risk

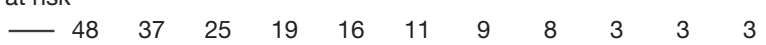

C

Local progression

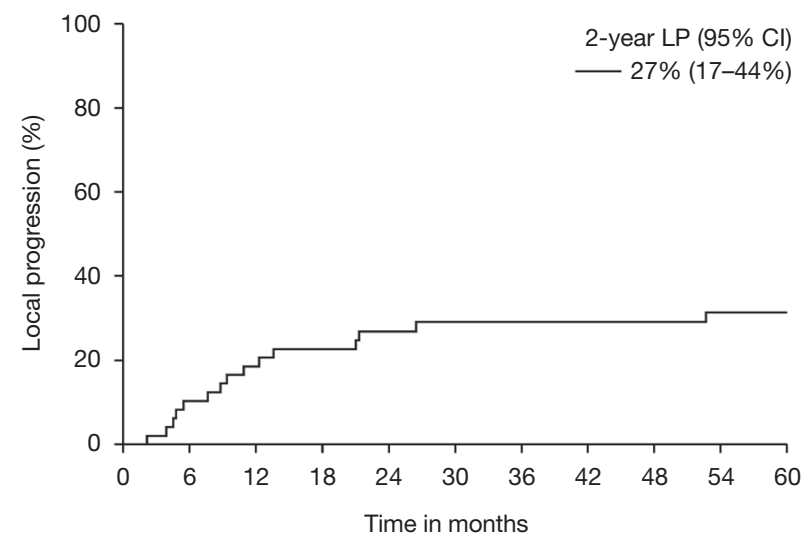

No. at risk

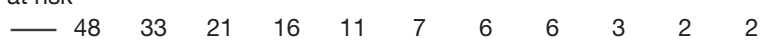

E

Distant metastasis

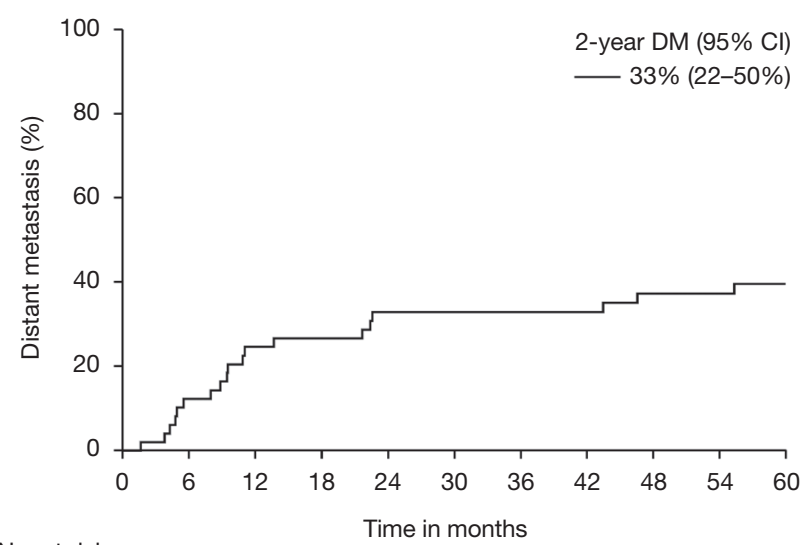

No. at risk

$$
\begin{array}{lllllllllll}
-48 & 32 & 22 & 18 & 13 & 10 & 8 & 9 & 3 & 3 & 2
\end{array}
$$

Figure 1 Estimated OS (A), PFS (B), LP (C), LRP (D) and DM (E).
B

Progression-free survival

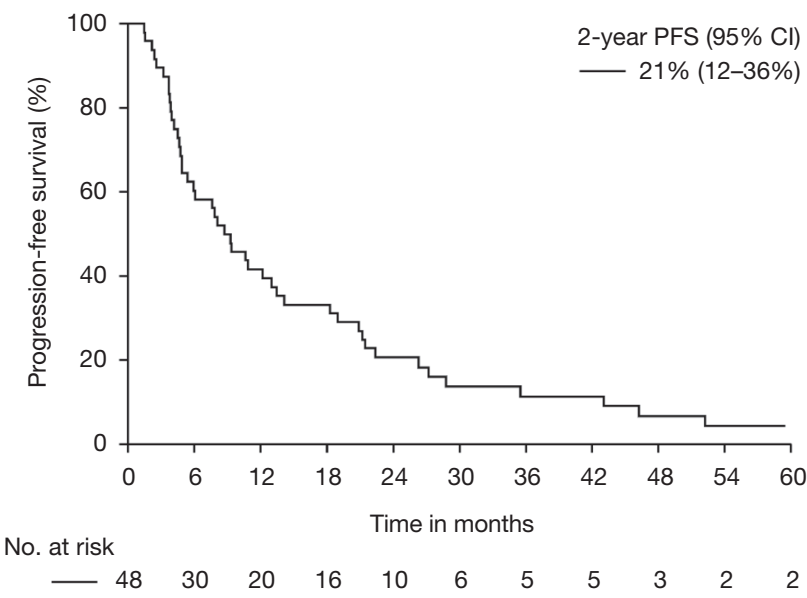

D Locoregional progression

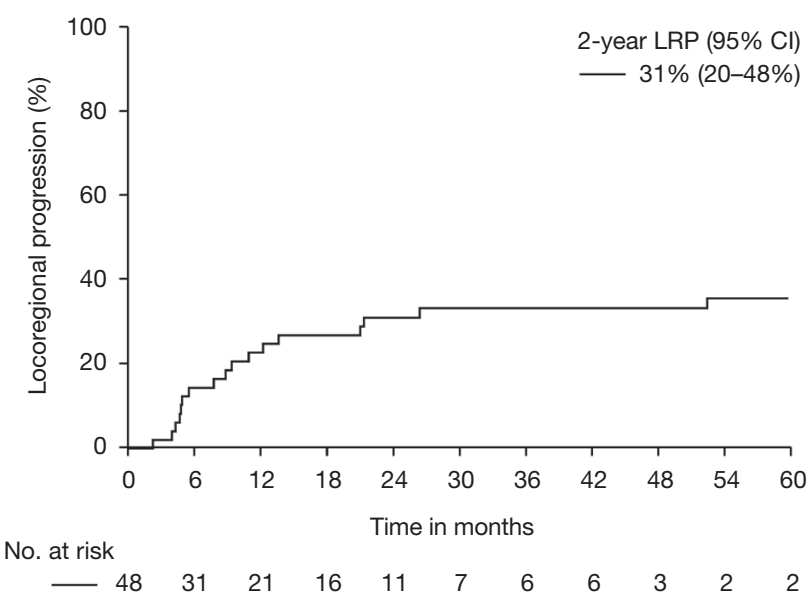


Table 4 Univariate associates with overall survival and progression-free survival

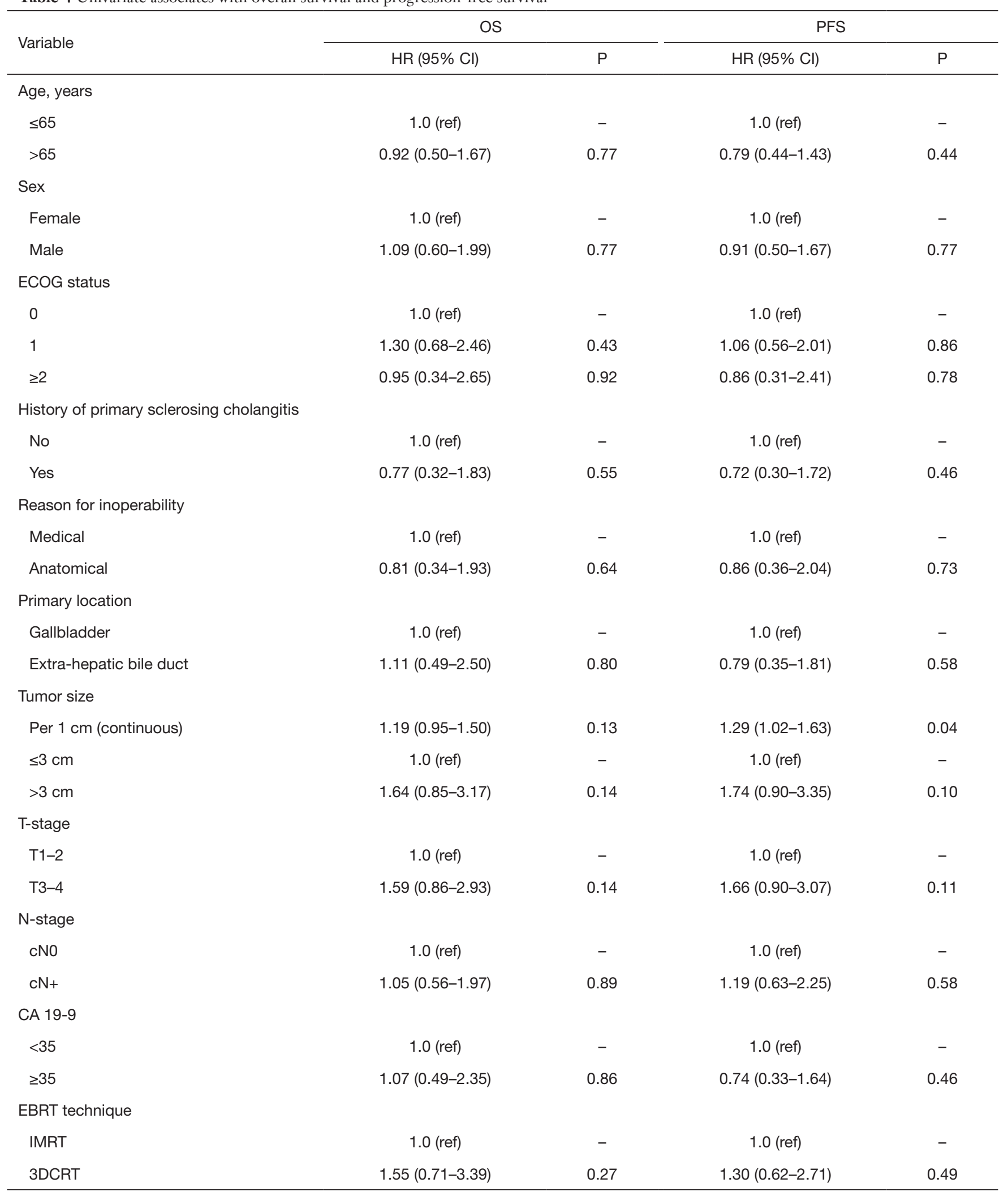

Table 4 (continued) 
Table 4 (continued)

\begin{tabular}{|c|c|c|c|c|}
\hline Variable & \multicolumn{2}{|c|}{ OS } & \multicolumn{2}{|c|}{ PFS } \\
\hline \multicolumn{5}{|l|}{ EBRT fractionation } \\
\hline Once-daily & 1.0 (ref) & - & 1.0 (ref) & - \\
\hline Twice-daily & $1.49(0.78-2.82)$ & 0.23 & $1.19(0.63-2.25)$ & 0.59 \\
\hline$\leq 59.5 \mathrm{~Gy}_{10}$ & 1.0 (ref) & - & 1.0 (ref) & - \\
\hline$>59.5 \mathrm{~Gy}_{10}$ & $0.40(0.18-0.92)$ & 0.03 & $0.37(0.16-0.84)$ & 0.02 \\
\hline \multicolumn{5}{|l|}{ Brachytherapy boost } \\
\hline No & 1.0 (ref) & - & 1.0 (ref) & - \\
\hline EBRT BED $\leq 59.5 \mathrm{~Gy}_{10}$ & 1.0 (ref) & - & 1.0 (ref) & - \\
\hline EBRT BED >59.5 $\mathrm{Gy}_{10}$ & $0.41(0.18-0.94)$ & 0.04 & $0.34(0.15-0.78)$ & 0.01 \\
\hline EBRT BED $\leq 59.5 \mathrm{~Gy}_{10}$ plus brachytherapy & $1.11(0.48-2.54)$ & 0.81 & $0.67(0.29-1.54)$ & 0.34 \\
\hline \multicolumn{5}{|l|}{ Elective lymph node Irradiation } \\
\hline No & 1.0 (ref) & - & 1.0 (ref) & - \\
\hline Yes & $0.86(0.26-2.82)$ & 0.81 & $0.92(0.28-3.00)$ & 0.89 \\
\hline \multicolumn{5}{|l|}{ Induction chemotherapy } \\
\hline No & 1.0 (ref) & - & 1.0 (ref) & - \\
\hline Yes & 1.0 (ref) & - & 1.0 (ref) & - \\
\hline No & $1.50(0.53-4.23)$ & 0.45 & $1.63(0.58-4.56)$ & 0.36 \\
\hline
\end{tabular}

OS, overall survival; PFS, progression-free survival; HR, hazard ratio; Cl, confidence interval; ECOG, Eastern Cooperative Oncology Group; EBRT, external beam radiotherapy; IMRT, intensity modulated radiotherapy; 3DCRT, three-dimensional conformal radiotherapy; RT, radiotherapy; $\mathrm{BED}$, biologically effective dose.

concurrent chemotherapy. Late toxicities of gastroduodenal ulceration and bleeding or cholangitis occurred in $42 \%$ and $50 \%$ of patients, respectively. Crane et al. reported on 52 patients treated between 1957 and 2000 with EBRT doses ranging between 30 and 85 Gy with concurrent 5-FU chemotherapy in $73 \%$ of patients (7). They demonstrated a median OS of 10 months and 2-year OS of $13 \%$. Grade 3 or higher AEs occurred in approximately $21 \%$ of patients.
Bisello et al. reported on 76 patients with unresectable biliary cancer (4\% intrahepatic cholangiocarcinoma; $96 \%$ EBC) treated between 1991 and 2017 with a median EBRT dose of 50 Gy, biliary brachytherapy in $51 \%$, and concurrent 5-FU or gemcitabine-based chemotherapy in $78 \%$ of patients (8). They demonstrated a median OS of 13.5 months, 2 -year OS of $26 \%$, and 3 -year OS of $11 \%$. Acute grade 3 GI AEs occurred in 13\% of patients. Yoshioka 
A

Overall survival

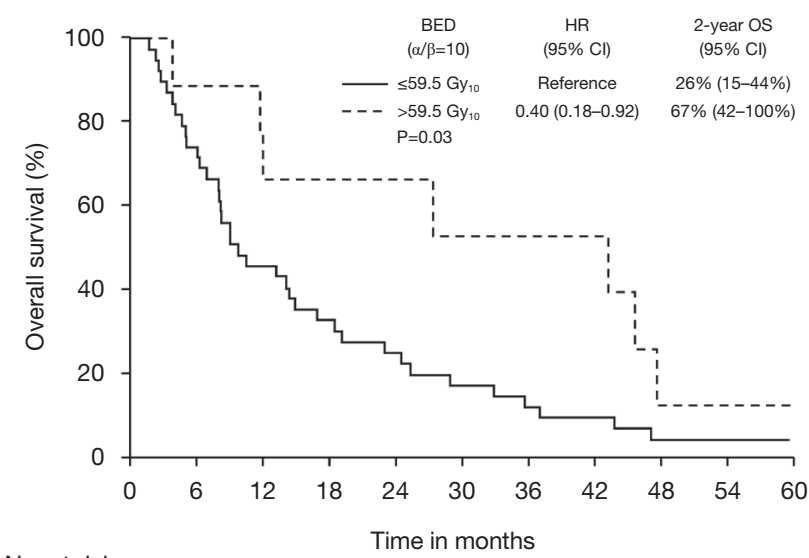

No. at risk

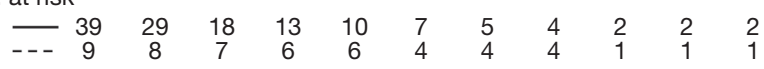

B

Progression-free survival

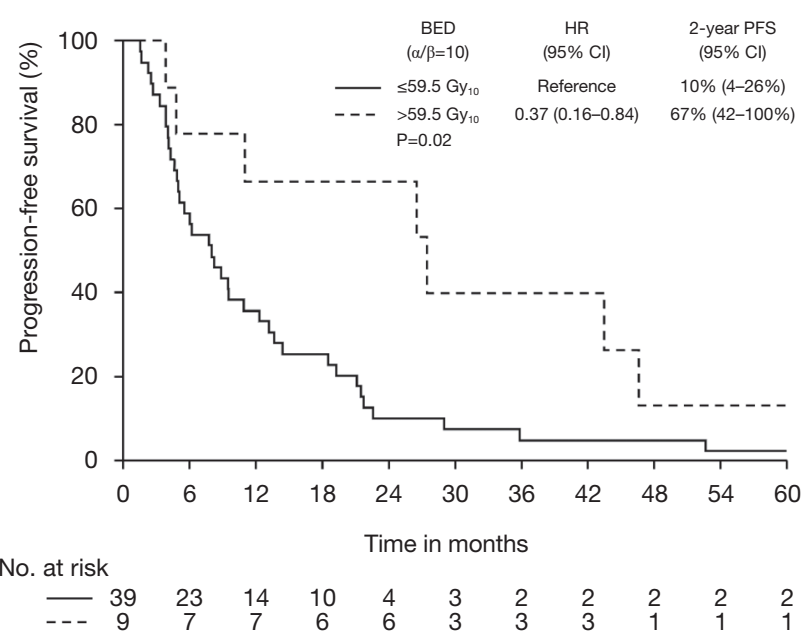

Figure 2 Survival estimates following RT for patients with EBC stratified by radiation dose. RT, radiotherapy; EBC, extra-hepatic biliary cancer.

Table 5 Late adverse events

\begin{tabular}{|c|c|c|}
\hline $\begin{array}{l}\text { Late adverse } \\
\text { events (G3+) }\end{array}$ & $\begin{array}{c}\text { 2-year (overall) } \\
\text { proportion }(95 \% \mathrm{Cl})\end{array}$ & $\begin{array}{l}\text { 2-year RT-related } \\
\text { proportion }(95 \% \mathrm{Cl})\end{array}$ \\
\hline Gl luminal toxicity & $27 \%$ (13 to 36$)$ & $17 \%$ (5 to 27$)$ \\
\hline Ulcer & $6 \%(0$ to 13$)$ & $2 \%(0$ to 6$)$ \\
\hline $\begin{array}{l}\text { Small bowel } \\
\text { obstruction }\end{array}$ & $4 \%(0$ to 10$)$ & $2 \%(0$ to 6$)$ \\
\hline GI bleed & $17 \%$ (5 to 27$)$ & $15 \%(4$ to 24$)$ \\
\hline Perforation & $2 \%$ (0 to 6$)$ & 0 \\
\hline Fistula & $2 \%$ (0 to 6$)$ & 0 \\
\hline Biliary Infection & $46 \%$ (30 to 58 ) & - \\
\hline
\end{tabular}

$\mathrm{Cl}$, confidence interval; G3+, grade 3 or higher; RT, radiotherapy;

Gl, gastrointestinal.

reported on 209 patients treated between 2000 and 2011 with EBRT to 50 Gy with concurrent chemotherapy in $78 \%$ of patients plus biliary brachytherapy in $27 \%$ (9). Twoyear OS was approximately $30 \%$. LC in these series ranged from $59-67 \%$. These outcomes compare similarly to our series with a median OS of 12.0 months, 2-year OS of $33 \%$, 3 -year OS of $20 \%$, and acute and late treatment-related GI AEs of $13 \%$ and $17 \%$. In summary, these retrospective data suggest that RT is associated with sustained survival in approximately $10-20 \%$ of patients and that these outcomes have been replicable amongst many institutions internationally, consistent across time, and reproducible despite substantial heterogeneity in patient, disease, and treatment characteristics.

Despite these findings, the question still remains whether the addition of RT improves outcomes compared to chemotherapy alone. The Advanced Biliary Cancer Trial-02 (ABC-02) randomized 410 patients with metastatic $(76 \%)$ or locally advanced and unresectable (24\%) biliary tract cancer to receive chemotherapy with gemcitabine or gemcitabine plus cisplatin and demonstrated an improvement in PFS and OS with the addition of cisplatin, thereby establishing the current standard of care chemotherapy regimen for this cohort (5). The median OS was 11.7 months and only 5 (1\%) patients were alive and disease-free at 2 years suggesting that despite improved median OS with combination chemotherapy, chemotherapy alone offers limited chance of long-term survival and disease control. To assess the potential benefit of the addition of RT, Torgeson et al. performed a propensity score-matched National Cancer Database analysis of 2996 patients with an unresectable EBC $(73 \%)$ or cancer of the Ampulla of Vater $(27 \%)$ treated with chemotherapy alone vs. CRT (15). CRT was associated with improved median OS (14.5 vs. 12.6 months, HR: 0.84, p<0.001). Similarly, Shinohara et al. performed a propensity-score matched analysis using the Surveillance, Epidemiology, and End Results database and demonstrated a median OS of 9 vs. 4 months (HR: 0.61, 95\% CI, $0.54-0.70, \mathrm{P}<0.0001)$ in favor of palliative RT vs. no RT or 
surgery (28).

Building upon these data, the Fédération Francophone de Cancérologie Digestive (FFCD) 9902 phase II randomized study compared treatment with 6 months of gemcitabine plus oxaliplatin $v s$. 5-FU and cisplatin-based CRT to a dose of 50 Gy (20). The study closed early due to slow accrual, but amongst the 36 accrued patients (anticipated accrual of 72 patients), there was no difference in median PFS (5.8 vs. 11.0 months, HR: 0.65 , 95\% CI: $0.32-1.33$ ) or median OS (13.5 vs. 19.9 months, HR: 0.69, 95\% CI: 0.31-1.55) and acute grade $3-4$ toxicity ( $47 \%$ vs. $75 \%$ ) for the CRT $v s$. chemotherapy alone cohorts, respectively. Hence, the role of RT for patients with unresectable EBC remains of debate but it is a treatment strategy supported per National Comprehensive Cancer Network guidelines (33). Our data do support the utility of RT, with a suggestion for 3-and 5 -year survival in a small subset, but we acknowledge these data are hypothesis generating, may be limited to highly select subsets of patients, and should be verified in the context of a prospective trial.

As suggested in other series comparing biliary stenting $v s$. biliary stenting plus RT (21-23), the FFCD 9902 trial also suggested a potentially meaningful palliative role for RT with a lower rate of biliary complications ( $28 \%$ vs. $44 \%$ ), such as obstruction with cholangitis, in the cohort receiving CRT compared with chemotherapy alone (20). In our series, the 2-year incidence of biliary infection was $46 \%, 1$ patient was able to become stent-free following RT, and all 3 patients who did not require pre-treatment biliary stenting remained stent-free following RT. Considering our cohort selection with very advanced disease not amenable to any form of surgical resection and correlating our findings with the aforementioned studies, we propose that RT may serve a palliative cytoreductive role to improve biliary obstruction for patients with more limited volume disease, delay biliary obstruction in patients not currently obstructed, and help prevent biliary stent tumor overgrowth, but has limited capacity in reversing biliary obstruction in patients with an extensive disease burden.

Interestingly, we identified an association between improved OS and PFS with an EBRT BED >59.5 Gy $\mathrm{y}_{10}$ and no significant increase in AEs for dose-escalated regimens. These findings have been more strongly demonstrated in cohorts of patients with intrahepatic cholangiocarcinoma (I-CCA) for which dose escalation to a dose $\geq 60$ Gy (34) or a $\mathrm{BED}>80.5 \mathrm{~Gy}_{10}(35)$ has been associated with improved $\mathrm{LC}$ and OS. A challenge with $\mathrm{EBC}$ is the anatomical location and close proximity to highly sensitive organs, such as the duodenum which has limited capacity to tolerate RT doses above $55 \mathrm{~Gy}$, without potentially life-threatening toxicity (36-38). Crane et al. evaluated the association between EBRT doses of 30 Gy, 36-50.4 Gy, and 54-85 Gy with outcomes for patients with EBC (7). They identified a prolonged median time to LP of $9 v s .11$ vs. 15 months and no significant increase in toxicity, suggesting a potential benefit of dose-escalation. Tsujino et al. demonstrated an association between improved OS and an EBRT dose of $\geq 45$ Gy (28) and Alden et al. demonstrated improved OS with EBRT dose >55 Gy (25). More recently however, Elganainy et al. compared patients treated with nonuniform dose escalation to a BED $>59.5 \mathrm{~Gy}_{10}$ to segments of tumor away from small bowel $v s$. conventional EBRT to a $\mathrm{BED} \leq 59.5 \mathrm{~Gy}_{10}$ and did not demonstrate any significant differences in OS or freedom from LP (18). Despite the suggestion of improved outcomes with dose-escalation seen in some series, there is a high likelihood of patient selection bias with tumors situated away from small bowel being more likely to receive dose escalation. Therefore, if considering dose escalation, each patient should be critically assessed for the feasibility and optimal technique based upon individual patient anatomy. If deemed suitable for dose escalation, priority should still be given to meeting acceptable RT doses to adjacent organs at risk.

Stereotactic body radiotherapy (SBRT) has also been explored as a potentially curative RT strategy for patients with biliary cancer. Sandler et al. reported on a cohort of 31 patients with either intra-hepatic cholangiocarcinoma $(19 \%)$ or extra-hepatic cholangiocarcinoma $(81 \%)$ who received SBRT to a median dose of 40 Gy in 5 fractions (39). The median OS was 15.7 months, 2-year OS was $33 \%$, and 2 -year LC was $47 \%$. Severe late AEs occurred in $16 \%$ of patients, including $9 \%$ with grade 3-4 duodenal ulceration or bleeding. Kozak et al. reported on a similar cohort of 40 patients (62\% intra-hepatic cholangiocarcinoma; $38 \%$ extrahepatic cholangiocarcinoma) treated with SBRT to a median dose of 40 Gy in 5 fractions (40). Amongst those with extrahepatic cholangiocarcinoma, the median OS was 10 months, LP occurred in $30 \%$, and acute and late hepatobiliary AEs occurred in $40 \%$ and $43 \%$-most commonly diseaserelated biliary infection. Regional recurrences occurred in $24 \%$ of patients, which is consistent with patterns of recurrence following curative-intent surgery which were identified most commonly within lymph nodes along the hepatoduodenal ligament, celiac artery, superior mesenteric artery, or retroperitoneal/para-aortic (41-44). In our series, $92 \%$ of patients received elective regional lymph node 
irradiation and no patient experienced an isolated regionalonly first-progression. Therefore, while SBRT may offer comparable LC and toxicity, more comprehensive regional lymph node coverage may be considered when offering RT to help prevent regional recurrence and perhaps could be included in future SBRT strategies which simultaneously treat elective lymph node regions to a lower RT dose.

Limitations of our study include the retrospective design, likely selection biases for RT, and small patient numbers. Conclusions regarding the role of RT would be strengthened if compared against a reference group receiving chemotherapy alone. There was potential underestimation of acute and late treatment-related AEs due to the retrospective nature of data collection for some patients. The addition of patient-reported outcomes would have strengthened this report, but unfortunately, were unavailable for most patients. Assessments of tumor and treatment characteristics associated with outcomes were limited by patient numbers, and therefore should be considered hypothesis-generating.

Further investigations are needed to optimize supportive and medical management, patient selection with radiographic response assessments and potential molecular or biological stratification, including isocitrate dehydrogenase-1 or fibroblast growth factor receptor mutational status, and incorporation of advanced RT technologies to help mitigate toxicities of treatment $(24,29)$. Few patients in our series received initial multiagent systemic therapy before CRT. This multi-modality treatment sequencing strategy, similar to the approach taken with locally advanced pancreas cancer and that attempted with the NRG-GI001 trial $(45,46)$, is now more commonly utilized and may serve as a patient selection tool prior to aggressive local therapy. While not demonstrated in our series of patients with highly advanced disease deemed unsuitable for surgery, pre-operative CRT may also be explored for patients with "borderline resectable" EBC to maximize the opportunity for margin negative, potentially curative resection (47).

\section{Conclusions}

RT is associated with 3- and 5-year survival in a subset of patients with unresectable EBC although patients remain at significant risk of both tumor- and treatment-related morbidity. Further exploration of the role of RT as part of a multi-modality curative treatment strategy is warranted.

\section{Acknowledgments}

Funding: None.

\section{Footnote}

Reporting Checklist: The authors have completed the STROBE reporting checklist. Available at http://dx.doi. org/10.21037/jgo-20-245

Data Sharing Statement: Available at http://dx.doi. org/10.21037/jgo-20-245

Conflicts of Interest: All authors have completed the ICMJE uniform disclosure form (available at http://dx.doi. org/10.21037/jgo-20-245). KRJ reports that he receives honoraria from RadOncQuestions.com, LLC. The other authors have no conflicts of interest to declare.

Ethical Statement: The authors are accountable for all aspects of the work in ensuring that questions related to the accuracy or integrity of any part of the work are appropriately investigated and resolved. The study was conducted in accordance with the Declaration of Helsinki (as revised in 2013). The study was approved by our institutional review board of the Mayo Clinic in Rochester, Minnesota (No. 18-003400) as a retrospective study deemed as minimal risk and exempt of the need for informed consent for individual participants included in the study.

Open Access Statement: This is an Open Access article distributed in accordance with the Creative Commons Attribution-NonCommercial-NoDerivs 4.0 International License (CC BY-NC-ND 4.0), which permits the noncommercial replication and distribution of the article with the strict proviso that no changes or edits are made and the original work is properly cited (including links to both the formal publication through the relevant DOI and the license). See: https://creativecommons.org/licenses/by-nc-nd/4.0/.

\section{References}

1. Ben-Josef E, Guthrie KA, El-Khoueiry AB, et al. SWOG S0809: A Phase II Intergroup Trial of Adjuvant Capecitabine and Gemcitabine Followed by Radiotherapy and Concurrent Capecitabine in Extrahepatic Cholangiocarcinoma and Gallbladder Carcinoma. J Clin Oncol 2015;33:2617-22. 
2. Horgan AM, Amir E, Walter T, et al. Adjuvant therapy in the treatment of biliary tract cancer: a systematic review and meta-analysis. J Clin Oncol 2012;30:1934-40.

3. Rea DJ, Munoz-Juarez M, Farnell MB, et al. Major hepatic resection for hilar cholangiocarcinoma: analysis of 46 patients. Arch Surg 2004;139:514-23; discussion 523-5.

4. Shroff RT, Kennedy EB, Bachini M, et al. Adjuvant Therapy for Resected Biliary Tract Cancer: ASCO Clinical Practice Guideline. J Clin Oncol 2019;37:1015-27.

5. Valle J, Wasan H, Palmer DH, et al. Cisplatin plus gemcitabine versus gemcitabine for biliary tract cancer. $\mathrm{N}$ Engl J Med 2010;362:1273-81.

6. Foo ML, Gunderson LL, Bender CE, et al. External radiation therapy and transcatheter iridium in the treatment of extrahepatic bile duct carcinoma. Int J Radiat Oncol Biol Phys 1997;39:929-35.

7. Crane CH, Macdonald KO, Vauthey JN, et al. Limitations of conventional doses of chemoradiation for unresectable biliary cancer. Int J Radiat Oncol Biol Phys 2002;53:969-74.

8. Bisello S, Buwenge M, Palloni A, et al. Radiotherapy or Chemoradiation in Unresectable Biliary Cancer: A Retrospective Study. Anticancer Res 2019;39:3095-100.

9. Yoshioka Y, Ogawa K, Oikawa H, et al. Impact of intraluminal brachytherapy on survival outcome for radiation therapy for unresectable biliary tract cancer: a propensity-score matched-pair analysis. Int J Radiat Oncol Biol Phys 2014;89:822-9.

10. Takamura A, Saito H, Kamada T, et al. Intraluminal lowdose-rate 192Ir brachytherapy combined with external beam radiotherapy and biliary stenting for unresectable extrahepatic bile duct carcinoma. Int J Radiat Oncol Biol Phys 2003;57:1357-65.

11. Deodato F, Clemente G, Mattiucci GC, et al. Chemoradiation and brachytherapy in biliary tract carcinoma: long-term results. Int J Radiat Oncol Biol Phys 2006;64:483-8.

12. Brunner TB, Schwab D, Meyer T, et al. Chemoradiation may prolong survival of patients with non-bulky unresectable extrahepatic biliary carcinoma. A retrospective analysis. Strahlenther Onkol 2004;180:751-7.

13. Bowling TE, Galbraith SM, Hatfield AR, et al. A retrospective comparison of endoscopic stenting alone with stenting and radiotherapy in non-resectable cholangiocarcinoma. Gut 1996;39:852-5.

14. Schleicher UM, Staatz G, Alzen G, et al. Combined external beam and intraluminal radiotherapy for irresectable Klatskin tumors. Strahlenther Onkol
2002;178:682-7.

15. Torgeson A, Lloyd S, Boothe D, et al.

Chemoradiation Therapy for Unresected Extrahepatic Cholangiocarcinoma: A Propensity Score-Matched Analysis. Ann Surg Oncol 2017;24:4001-8.

16. Autorino R, Mattiucci GC, Ardito F, et al. Radiochemotherapy with Gemcitabine in Unresectable Extrahepatic Cholangiocarcinoma: Long-term Results of a Phase II Study. Anticancer Res 2016;36:737-40.

17. Ben-David MA, Griffith KA, Abu-Isa E, et al. External-beam radiotherapy for localized extrahepatic cholangiocarcinoma. Int J Radiat Oncol Biol Phys 2006;66:772-9.

18. Elganainy D, Holliday EB, Taniguchi CM, et al. Dose escalation of radiotherapy in unresectable extrahepatic cholangiocarcinoma. Cancer Med 2018;7:4880-92.

19. Chen SC, Chen MH, Li CP, et al. External beam radiation therapy with or without concurrent chemotherapy for patients with unresectable locally advanced hilar cholangiocarcinoma. Hepatogastroenterology 2015;62:102-7.

20. Phelip JM, Vendrely V, Rostain F, et al. Gemcitabine plus cisplatin versus chemoradiotherapy in locally advanced biliary tract cancer: Federation Francophone de Cancerologie Digestive 9902 phase II randomised study. Eur J Cancer 2014;50:2975-82.

21. Valek V, Kysela P, Kala Z, et al. Brachytherapy and percutaneous stenting in the treatment of cholangiocarcinoma: a prospective randomised study. Eur J Radiol 2007;62:175-9.

22. Tan Y, Zhu JY, Qiu BA, et al. Percutaneous biliary stenting combined with radiotherapy as a treatment for unresectable hilar cholangiocarcinoma. Oncol Lett 2015;10:2537-42.

23. Isayama $H$, Tsujino $T$, Nakai $Y$, et al. Clinical benefit of radiation therapy and metallic stenting for unresectable hilar cholangiocarcinoma. World J Gastroenterol 2012;18:2364-70.

24. Makita C, Nakamura T, Takada A, et al. Clinical outcomes and toxicity of proton beam therapy for advanced cholangiocarcinoma. Radiat Oncol 2014;9:26.

25. Alden ME, Mohiuddin M. The impact of radiation dose in combined external beam and intraluminal Ir-192 brachytherapy for bile duct cancer. Int J Radiat Oncol Biol Phys 1994;28:945-51.

26. Moureau-Zabotto L, Turrini O, Resbeut M, et al. Impact of radiotherapy in the management of locally advanced extrahepatic cholangiocarcinoma. BMC Cancer 2013;13:568. 
27. Ghafoori AP, Nelson JW, Willett CG, et al. Radiotherapy in the treatment of patients with unresectable extrahepatic cholangiocarcinoma. Int J Radiat Oncol Biol Phys 2011;81:654-9.

28. Shinohara ET, Mitra N, Guo M, et al. Radiotherapy is associated with improved survival in adjuvant and palliative treatment of extrahepatic cholangiocarcinomas. Int J Radiat Oncol Biol Phys 2009;74:1191-8.

29. Kasuya G, Terashima K, Shibuya K, et al. Carbon-ion radiotherapy for cholangiocarcinoma: a multi-institutional study by and the Japan carbon-ion radiation oncology study group (J-CROS). Oncotarget 2019;10:4369-79.

30. Lee KJ, Yi SW, Cha J, et al. A pilot study of concurrent chemoradiotherapy with gemcitabine and cisplatin in patients with locally advanced biliary tract cancer. Cancer Chemother Pharmacol 2016;78:841-6.

31. Tsujino K, Landry JC, Smith RG, et al. Definitive radiation therapy for extrahepatic bile duct carcinoma. Radiology 1995;196:275-80.

32. Darwish Murad S, Kim WR, Harnois DM, et al. Efficacy of neoadjuvant chemoradiation, followed by liver transplantation, for perihilar cholangiocarcinoma at 12 US centers. Gastroenterology 2012;143:88-98.e3; quiz e14.

33. NCCN. NCCN Clinical Practice Guidelines in Oncology: Biliary Tract Cancers: Extrahepatic Cholangiocarcinoma. Version 1.2020. 2020. Available online: https://www.nccn. org/professionals/physician_gls/default.aspx

34. Hong TS, Wo JY, Yeap BY, et al. Multi-Institutional Phase II Study of High-Dose Hypofractionated Proton Beam Therapy in Patients With Localized, Unresectable Hepatocellular Carcinoma and Intrahepatic Cholangiocarcinoma. J Clin Oncol 2016;34:460-8.

35. Tao R, Krishnan S, Bhosale PR, et al. Ablative Radiotherapy Doses Lead to a Substantial Prolongation of Survival in Patients With Inoperable Intrahepatic Cholangiocarcinoma: A Retrospective Dose Response Analysis. J Clin Oncol 2016;34:219-26.

36. Stanic S, Mayadev JS. Tolerance of the small bowel to therapeutic irradiation: a focus on late toxicity in patients receiving para-aortic nodal irradiation for gynecologic malignancies. Int J Gynecol Cancer 2013;23:592-7.

37. Verma J, Sulman EP, Jhingran A, et al. Dosimetric predictors of duodenal toxicity after intensity modulated radiation therapy for treatment of the para-aortic nodes in gynecologic cancer. Int J Radiat Oncol Biol Phys 2014;88:357-62.

38. Kelly P, Das P, Pinnix CC, et al. Duodenal toxicity after fractionated chemoradiation for unresectable pancreatic cancer. Int J Radiat Oncol Biol Phys 2013;85:e143-9.

39. Sandler KA, Veruttipong D, Agopian VG, et al. Stereotactic body radiotherapy (SBRT) for locally advanced extrahepatic and intrahepatic cholangiocarcinoma. Adv Radiat Oncol 2016;1:237-43.

40. Kozak MM, Toesca DAS, von Eyben R, et al. Stereotactic Body Radiation Therapy for Cholangiocarcinoma: Optimizing Locoregional Control With Elective Nodal Irradiation. Adv Radiat Oncol 2020;5:77-84.

41. Choi HS, Kang KM, Jeong BK, et al. Patterns of failure after resection of extrahepatic bile duct cancer: implications for adjuvant radiotherapy indication and treatment volumes. Radiat Oncol 2018;13:85.

42. Jarnagin WR, Ruo L, Little SA, et al. Patterns of initial disease recurrence after resection of gallbladder carcinoma and hilar cholangiocarcinoma: implications for adjuvant therapeutic strategies. Cancer 2003;98:1689-700.

43. Koo TR, Eom KY, Kim IA, et al. Patterns of failure and prognostic factors in resected extrahepatic bile duct cancer: implication for adjuvant radiotherapy. Radiat Oncol J 2014;32:63-9.

44. Zhou W, Qian L, Rong Y, et al. Prognostic factors and patterns of recurrence after curative resection for patients with distal cholangiocarcinoma. Radiother Oncol 2020;147:111-7.

45. Hammel P, Huguet F, van Laethem JL, et al. Effect of chemoradiotherapy vs chemotherapy on survival in patients with locally advanced pancreatic cancer controlled after 4 months of gemcitabine with or without erlotinib: the LAP07 randomized clinical trial. Jama 2016;315:1844-53.

46. NRG GI-001: Radiation Therapy vs. Observation Following Gemcitabine and Cisplatin for Inoperable Localized Liver Cancer. Available online: https:// clinicaltrials.gov/ct2/show/NCT02200042

47. Katz MH, Pisters PW, Evans DB, et al. Borderline resectable pancreatic cancer: the importance of this emerging stage of disease. J Am Coll Surg 2008;206:83346; discussion 846-8.

Cite this article as: Jethwa KR, Sannapaneni S, Mullikin TC, Harmsen WS, Petersen MM, Antharam P, Laughlin B, Mahipal A, Halfdanarson TR, Merrell KW, Neben-Wittich M, Sio TT, Haddock MG, Hallemeier CL. Chemoradiotherapy for patients with locally advanced or unresectable extra-hepatic biliary cancer. J Gastrointest Oncol 2020;11(6):1408-1420. doi: 10.21037/ jgo-20-245 
Table S1 Select series of curative-intent radiotherapy for extra-hepatic biliary cancers

\begin{tabular}{|c|c|c|c|c|c|c|c|c|c|c|c|}
\hline Author & Year & $\mathrm{N}$ & Disease site & Study design & $\begin{array}{l}\text { Concurrent chemo- } \\
\text { therapy }(\%)\end{array}$ & Median EBRT dose (Gy) & $\begin{array}{l}\text { Brachy-therapy } \\
(\%)\end{array}$ & os & PFS & Grade $3+$ acute toxicity & Late toxicity \\
\hline TakamuraSaito et al., 2003 & 1988 to 1998 & 93 & EBC: $100 \%$ & Retrospective & 0 & 50 & 100 & $\begin{array}{l}\text { mOS: } 12 \text { months; OS2: 15\%; OS3: 10\%; } \\
\text { OS5: } 4 \%\end{array}$ & - & - & $\begin{array}{l}\text { Bowel: G3: 11\%; Biliary (including } \\
\text { cholangitis) G3: } 5 \%\end{array}$ \\
\hline DeodatoClemente et al,, 2006 & 1991 to 1997 & 22 & EBC: $100 \%$ & Retrospective & 95 & 50.4 & 55 & mOS: 23 months; OS2: 41\%; OS3: 18\% & - & Gl: $0 \%$ & Bowel: G3: 9\% \\
\hline BrunnerSchwab et al., 2004 & 1994 to 2001 & 25 & EBC: $100 \%$ & Retrospective & 100 & 45 & 16 & mOS: 17 months & - & Nausea: 21\%; Diarrhea: 0\% & - \\
\hline Bowling Galbraith et al, 1996 & 1988 to 1994 & 28 & EBC: $100 \%$ & Retrospective & - & 30 & 100 & mOS: 10 months & - & - & - \\
\hline SchleicherStaatz et al., 2002 & 1991 to 1999 & 30 & EBC: $100 \%$ & Retrospective & 80 & 30 & 60 & $\begin{array}{l}\text { mOS: } 6 \text { months; EBRT vs. EBRT + } \\
\text { brachyytherapy: } 4 \text { months vs. } 9 \text { months (P=0.25) }\end{array}$ & - & - & - \\
\hline YoshiokaOgawa et al, 2014 & 2000 to 2011 & 209 & $\begin{array}{l}\text { EBC: } n / 2 \text { I-CCA: } n / a \\
\text { Ampullary cancer: n/a }\end{array}$ & Retrospective & 78 & 50 & 27 & $\begin{array}{l}\text { Brachytherapy yes vs. no: OS2: } 31 \% \text { vs. } 33 \% \\
(\mathrm{P}=0.34) \text {; } D S 52 \text { 42\% vs. } 37 \% \text { ( } P=0.079)\end{array}$ & - & - & - \\
\hline TorgesonLloyd et all, 2017 & 2004 to 2014 & Total 2,$966 ; 1,070$ RT & $\begin{array}{l}\text { EBC: } 73 \% \text { Ampullary } \\
\text { cancer: } 27 \%\end{array}$ & NCDB & 85 & 54 & - & $\begin{array}{l}\text { CRT vs. chemotherapy: mOS: } 15 \text { vs. } 13 \text { months } \\
(\mathrm{P}<0.001)\end{array}$ & & & \\
\hline AutorinoMattiucci et all, 2016 & 2002 to 2009 & 27 & EBC: $100 \%$ & Prospective Phase II & 100 & 50 & 22 & mOS: 14 months; OS2: 27\%; OS3: 7\% & & Hematologic: 19\%; Gl: 19\% & \\
\hline BiselloBuwenge et al., 2019 & 1991 to 2017 & 76 & EBC: $96 \%$ I-CCA: 4\% & Retrospective & 78 & 50 & 51 & mOS: 14 months; OS2: 26\%; OS3: 11\% & $\begin{array}{l}\text { mPFS: } 10 \text { months; } \\
\text { PFS2 9\%; PFS3 9\% }\end{array}$ & Hematologic: 8\%; Gl: 13\% & - \\
\hline Ben-DavidGriffith et al,, 2006 & 1986 to 2004 & 81 total, 52 unresectable & EBC: $100 \%$ & Retrospective & 54 & 60.2 & - & mOS: 13 months & mPFS: 8 months & $\begin{array}{l}\text { Nausea: } 1 \% \text {; Fatigue: } 2 \% \text {; } \\
\text { Cholangitis: } 6 \%\end{array}$ & Gl bleed: $3 \%$ \\
\hline ElganainyHolliday et al, 2018 & 2001 to 2015 & 80 & EBC: $100 \%$ & Retrospective & 86 & 50.4 BED: 59.5 Gy10 & - & $\begin{array}{l}\text { mOS: } 19 \text { months, } 17 \text { months, (perihilar), } \\
27 \text { months (distal) }\end{array}$ & - & $\begin{array}{l}\text { Gl: 11\%; Hematologic: 15\%; } \\
\text { Hospitalization: } 33 \%\end{array}$ & GI Bleed: $28 \%$ \\
\hline Sandlerveruttipong et al, 2016 & 2008 to 2015 & 31 & EBC: $81 \%$ I-CCA: $19 \%$ & Retrospective & - & 40 (SBRT) & - & mOS: 16 months; OS2: 33\% & $\begin{array}{l}\text { mPFS: } 17 \text { months; } \\
\text { PFS2: } 34 \%\end{array}$ & - & $\begin{array}{l}\text { Overall: 16\%; GI ulcer and bleed: 9\%; } \\
\text { Duodenal Obstruction: } 6 \%\end{array}$ \\
\hline ChenChen et al, 2015 & 2001 to 2010 & 34 total, $16 \mathrm{CRT}, 18 \mathrm{RT}$ & EBC: $100 \%$ & Retrospective & 47 & 54 & - & $\begin{array}{l}\text { mOS: } 10 \text { months; } C \text { CRT vs. RT mOS: } 14 \text { vs. } \\
7 \text { months }(P=0.003)\end{array}$ & $\begin{array}{l}\text { CRT vs. RT mPFS: } \\
9 \text { vs. } 4 \text { months } \\
(\mathrm{P}=0.005)\end{array}$ & - & - \\
\hline PhelipVendrely et all, 2014 & 2006 to 2010 & 34 total, 18 CRT, 16 Chemo & EBC: $100 \%$ & $\begin{array}{l}\text { Prospective Randomized } \\
\text { Phase II }\end{array}$ & 100 (in CRT arm) & 50 & - & CRT vs. Chemotherapy 14 vs. 20 months & $\begin{array}{l}\text { CRT vs. } \\
\text { Chemotherapy mPFS: } \\
6 \text { vs. } 11 \text { months }\end{array}$ & $\begin{array}{l}\text { Hossitalization: } 74 \% ; \text {; CRT vs. } \\
\text { Chemontherapy Overall: } 47 \% \\
\text { vs. } 75 \% ; \text { Hematologic: } 23 \% \\
\text { vs. 25\%; Gl: 12\% vs. } 6 \%\end{array}$ & $\begin{array}{l}\text { CRT vs. chemotherapy biliary: } 28 \% \text { vs. } \\
44 \%\end{array}$ \\
\hline MakitaNakamura et all, 2014 & 2009 to 2011 & 28 & $\begin{array}{l}\text { EBC: } 43 \% \text { Lymph node } \\
\text { recurrence: } 36 \% \text { I-CCA: } \\
21 \%\end{array}$ & Retrospective & 11 & 68.2 & - & OS1: $49 \%$ & PFS1: $30 \%$ & Biliary: $4 \%$ & $\begin{array}{l}\text { Duodenal ulcer: } 7 \% \text {; Gastric ulcer: 4\%; GI } \\
\text { Bleed: } 7 \% \text {; Duodenal stenosis: } 7 \%\end{array}$ \\
\hline ValekKysela et al, 2007 & to & 42 total, 21 Stent, 21 Stent + RT & EBC: $100 \%$ & Prospective RCT & - & 50 & 100 & $\begin{array}{l}\text { Stent + RT vs. Stent: } 13 \text { months vs. } 10 \text { months } \\
(P<0.05)\end{array}$ & - & - & - \\
\hline Alden and Mohiuddin 1994 & 1984 to 1990 & 48 total, 24 RT, 24 no RT & EBC: $100 \%$ & Retrospective & 79 & 46 & 67 & $\begin{array}{l}\text { RT vs. no RT } 12 \text { months vs. } 6 \text { months }(P=0.01) ; \\
\text { OS2: } 30 \% \text { vs. } 17 \%\end{array}$ & - & - & $\begin{array}{l}\text { Biliary infection: } 56 \% \text {; Biliary obstruction: } \\
\text { 17\% }\end{array}$ \\
\hline Moureau-ZabottoTurrin et al., 2013 & 1995 to 2008 & 30 & EBC: $100 \%$ & Retrospective & 60 & 48.25 & - & $\begin{array}{l}\text { mOS: } 12 \text { months; OS3: 15\% RT vs. CRT; OS1: } \\
\text { 28\% vs. } 67 \%(\mathrm{P}=0.15)\end{array}$ & $\begin{array}{l}\text { mPFS: } 9 \text { months; } \\
\text { PFSS: } 16 \% \text {; RT vs. } \\
\text { CRT PFS1: } 29 \% \text { vs. } \\
44 \% \text { ( } P=0.3)\end{array}$ & $\begin{array}{l}\text { Overall: 30\%; Nausea: 13\%; } \\
\text { Cholangitis: } 17 \%\end{array}$ & - \\
\hline GhafooriNelson et al., 2011 & 1992 to 2006 & 37 & EBC: $100 \%$ & Retrospective & $86 \%$ & 45 & 38 & mOS: 14 months; OS2: 22\% & - & Overall: $14 \%$ & - \\
\hline TsujinoLandry et al, 1995 & 1979 to 1993 & 27 & EBC: $100 \%$ & Retrospective & 15 & 45 & 74 & mOS: 13 months; OS2: 9\% & - & - & $\begin{array}{l}\text { Cholangitis: } 61 \% \text {; Gastric outlet } \\
\text { obstruction: } 9 \%\end{array}$ \\
\hline CraneMacdonald et al., 2002 & 1957 to 2000 & 52 & EBC: $100 \%$ & Retrospective & 73 & 30-85 & 6 & mOS: 10 months; OS2: 13\% & - & $\begin{array}{l}\text { Overall: } 21 \% ; \\
\text { Hospitalization: } 21 \%\end{array}$ & - \\
\hline KozakToesca et al, 2020 & 2003 to 2017 & 40 & I-CCA: $62 \%$ EBC: $38 \%$ & Retrospective & - & 40 (SBRT) & - & $\begin{array}{l}\text { mOS: } 23 \text { months I-CCA vs. Perihilar: } 23 \text { months } \\
\text { vs. } 10 \text { months }(P=0.018)\end{array}$ & - & $\begin{array}{l}\text { Non-hepatobiliary: } 3 \% \\
\text { Hepatobiliary: } 40 \%\end{array}$ & Non-hepatobiliary: $3 \%$; Hepatobiliary: $43 \%$ \\
\hline Kasuyaterashima et al, 2019 & 2005 to 2016 & 56 & EBC: $52 \%$ I-CCA: $48 \%$ & Retrospective & 2 & 76 & - & $\begin{array}{l}\text { mOS: } 15 \text { months; OS2: } 41 \% \text { Perihilar only: } \\
\text { mOS: } 13 \text { months; OS2: } 26 \%\end{array}$ & $\begin{array}{l}\text { mPFS: } 9 \text { months; } \\
\text { PFS2: } 32 \%\end{array}$ & - & Liver: $2 \%$ \\
\hline FooGunderson et al., 1997 & 1980 to 1991 & 24 & EBC: $100 \%$ & Retrospective & 38 & 50.4 & 100 & mOS: 13 months; OS2: 19\%; OS5: 14\% & PFS5: 13\% & Hospitalization: $8 \%$ & $\begin{array}{l}\text { Cholangitis: } 50 \% \text {; Gl ulcer with bleeding: } \\
42 \%\end{array}$ \\
\hline LeeYi et al., 2016l & 2007 to 2011 & 18 & EBC: $100 \%$ & Prospective Pillot & 100 & 45 & 0 & mOS: 10 months & mPFS: 7 months & $\begin{array}{l}\text { Thrombocytopenia: } 33 \% ; \\
\text { Anemia: } 11 \% \text { Neutropenia: } \\
6 \% ; \text { Non-hhatologic: } 6 \%\end{array}$ & - \\
\hline TanZhu et al, 2015 & 2007 to 2013 & 38 total, 13 Stent, 25 Stent + RT & EBC: $100 \%$ & Retrospective & - & $37-40.7$ & - & mOS: 12 months & - & - & - \\
\hline IsayamaTsujino et al, 2012 & 1986 to 2008 & 39 total, 11 Stent, 28 Stent + RT & EBC: $100 \%$ & Retrospective & 0 & 54 & $39 \%$ & $\begin{array}{l}\text { Stent vs. Stent + EBRT } 6 \text { months vs. } 22 \text { months } \\
(P=0.0031)\end{array}$ & _ & - & GI ulcer and bleed: $18 \%$ \\
\hline
\end{tabular}

Bent, external beam radiotherapy, OS, overall survival; PFS, progression-rree sunvival;
BED, biologically effective dose; SBRT, stereotactic body radiotherapy; RT, radiotherapy 